\title{
Comparison of long-chain fatty acids and alkanes as markers to estimate diet composition of equines and cattle consuming heathland vegetation species
}

\author{
L.M.M. Ferreira ${ }^{\text {a, } *}$, R. Celaya ${ }^{\text {b }}$, A.S. Santos ${ }^{\text {a }}$, V. Falco ${ }^{c}$, C. Guedes ${ }^{a}$, M.A.M. Rodrigues ${ }^{\text {a }}$, K. Osoro ${ }^{\text {b }}$ \\ a CECAV- Departamento de Zootecnia, Universidade de Trás-os-Montes e Alto Douro, PO Box 1013, 5001-801 Vila Real, Portugal \\ b SERIDA- Servicio Regional de Investigación y Desarrollo Agroalimentario, PO Box 13, 33300 Villaviciosa, Asturias, Spain \\ c CQ-VR, Centro de Química - Vila Real, Departmento de Agronomia, Universidade de Trás-os-Montes e Alto Douro, Apartado 1013, 5001-801 Vila Real, Portugal
}

\section{A R T I C L E I N F O}

\section{Article history:}

Received 12 February 2010

Received in revised form 7 April 2010

Accepted 9 April 2010

\section{Keywords:}

Equines

Cattle

Long-chain fatty acids

Alkanes

Diet composition

Heathland

\begin{abstract}
A B S T R A C T
This study aimed to evaluate the application of long-chain fatty acids (LCFA) as an alternative or as a complement to alkanes to estimate diet composition in equines and cattle. Twelve mature crossbreed mares ( $385 \pm 47 \mathrm{~kg}$ live weight - LW) and 6 adult non-lactating cows ( $499 \pm 36 \mathrm{~kg}$ LW) of Asturiana de los Valles breed were divided in groups of 3 animals and housed in individual stalls. Animals received a daily total amount of $1.0 \mathrm{~kg} \mathrm{DM} / 100 \mathrm{~kg}$ LW of different diets composed of herbaceous (Lolium perenne) and woody species (Ulex gallii and heather). Diet composition was estimated from LCFA (i.e., $C_{22}-C_{34}$ ) and alkane (i.e., $C_{25}-C_{31}$ and $C_{33}$ ) concentrations in diet and faeces by least-squares procedures, using marker faecal concentrations uncorrected for incomplete faecal recovery (FCO), corrected using mean recovery rate of the dietary treatment that the animal belonged to (FC1), or corrected using mean recovery rate across all experimental diets (FC2). For all diet components, LCFA concentrations were higher than the alkane ones, with even-chain LCFA accounting for more than 0.80 of total LCFA. In general, faecal recovery (FR) of the markers was incomplete and related to their carbon-chain length. In equines, the FR of both markers tended to decrease with carbon-chain length in a curvilinear fashion $(P<0.001)$, whereas in cattle LCFA and alkane FR tended to increase with carbon-chain length in a curvilinear $(P<0.001)$ and linear $(P<0.001)$ fashion, respectively. Diet composition had an effect $(P<0.001)$ on the LCFA and alkane FR in both animal species, and, in equines, seemed to be related with diet digestibility, i.e., decrease of marker disappearance from the digestive tract with a decrease of diet digestibility. In general, diet composition estimates based on LCFA alone were more accurate than those obtained using alkanes alone. Combination of LCFA and alkane markers resulted in an increase $(P<0.05)$ in the accuracy of diet estimates in both animal species, indicating a higher discriminatory power among plant species. The use of FCO and FC2 resulted in the worst $(P<0.05)$ estimates of diet composition, while high levels of accuracy were observed when using more accurate faecal corrections (FC1). Results showed that LCFA can be useful markers for studying diet selection of equines and cattle grazing on heathland vegetation communities, if a proper adjustment of their faecal concentrations prior to their application is applied. It is also concluded that use of LCFA in combination with alkanes can increase the accuracy of diet composition estimates.
\end{abstract}

(c) 2010 Elsevier B.V. All rights reserved.

\section{Introduction}

Heathlands are shrubby vegetation communities widespread in the northwest of the Iberian Peninsula as a

\footnotetext{
* Corresponding author. Tel.: + 35 1259350421; fax: + 351259325058.

E-mail address: Imf@utad.pt (L.M.M. Ferreira).
}

consequence of the abandonment of agricultural and livestock managements initiated in the 1950s, and by frequent forest fires. Feral cattle and equines use these vegetation areas in free-ranging systems, generally in completely wild conditions with minimal management. In general, there is a lack of technical and scientific knowledge on how these herds behave (i.e., grazing paths, foraging behaviour, etc.) and their influence on the dynamics of the vegetation community. 
Although cattle and equines show clear morpho-physiological differences (e.g., food prehension, digestive strategies, etc.), it seems that they present a high degree of dietary overlap and, consequently, a high competition for the available biomass. In fact, overlap levels higher than $70 \%$ have been recorded between these animal species in very different ecosystems such as North American sagebrush steppe (Krysl et al., 1984), African thornbush savannah (Lechner-Doll et al., 1995) and European Pyrenean pastures (Aldezabal, 2001), with an intensive utilization of the grass biomass in all situations. Their co-existence in very diverse ecosystems results of different digestive strategies (Duncan et al., 1990; LechnerDoll et al., 1995), conferring them alternative abilities to use the same feed resources (Menard et al., 2002; Loucougaray et al., 2004). Studies conducted in upland vegetation communities showed that in the beginning of the grazing season equines and cattle showed an intensive use of grasslands due to the high availability of herbage of better nutritive quality, increasing the selection of woody species as herbage availability decreases (Osoro et al., 2008). In fact, equines were able to include high amounts (up to 30\%) of woody species in their diets at the end of the grazing season (Osoro et al., 2008). Cattle hardly select green shoots of shrubs such as heathers (Erica spp., Calluna vulgaris) and gorse (Ulex gallii) (Aldezabal, 2001; Celaya et al., 2007), due to their muzzle anatomy (Illius and Gordon, 1993).

Alkanes have been used as faecal markers for estimating diet composition of different domestic herbivore species in heathlands with or without associated improved pastures (Celaya et al., 2007; Osoro et al., 2007). However, some plant species that can be found in these complex vegetation communities (Lolium perenne, Trifolium repens, Pseudarrhenatherum longifolium, Agrostis capillaris and U. gallii) present very low alkane concentrations, making them more prone to measurement errors (Brosh et al., 2003; Dove and Mayes, 2006), and their discrimination more difficult to accomplish (Charmley and Dove, 2007). This problem is even more important in the end of the grazing season due to a maturity stage effect on alkane concentrations (Dove et al., 1996), which Smith et al. (2001) related to an increase of the stem fraction in the whole plant, characterized by lower alkane concentrations than the leaf fraction. Moreover, recent results suggest difficulties in distinguishing herbaceous species and/or herbaceous species and gorse (U. gallii) due to similarities in their alkane profile, leading to diet composition estimation more prone to bias (Oliván et al., 2007; Ferreira et al., 2009a). An increase in the discriminatory power between these plant species can be accomplished by combining the alkanes with other epicuticular wax components such as long-chain fatty acids (LCFA, Dove and Mayes, 2006)

The objective of the present work was to assess the utilization of LCFA or LCFA + alkanes to estimate the diet composition of equines and cattle fed on browse and herb feeds of the end of the grazing season, and to compare these estimates with those obtained using only the alkanes.

\section{Materials and methods}

This study was conducted in the end of the grazing and vegetation growth season of 2004 (i.e., November and December) at Carbayal Research Station, situated at 9001000 masl, at San Isidro's Mountain, Asturias, Spain (longitude $-6^{\circ} 53^{\prime}$, latitude $43^{\circ} 20^{\prime}$ ), established on natural heather-gorse shrubland vegetation with or without adjacent areas of improved pasture (L. perenne and T. repens).

\subsection{Animals, experimental design and diets}

Twelve mature crossbreed mares $(385 \pm 47 \mathrm{~kg}$ live weight, LW) and six adult non-lactating cows $(499 \pm 36 \mathrm{~kg} \mathrm{LW})$ of Asturiana de los Valles breed were used in a 11 day experiment. Groups of 3 animals were assigned at random to one of four (E1, E2, E3 and E4 for equines) and two (C1 and C2 for cattle) diets that aimed to reflect the grazing behaviour of these animal species on these vegetation communities in the end of the grazing season (Osoro et al., 2005). Diet 1 (E1 and C1) contained only ryegrass (L. perenne), diet 2 (E2 and $\mathrm{C} 2$ ) included ryegrass (0.70) and heather (0.30), diet 3 (E3) consisted of ryegrass (0.70) and gorse (U. gallii, 0.30 ), and diet 4 (E4) was composed of ryegrass (0.40), gorse (0.30) and heather (0.30). Heather represented the proportions of Erica umbellata, Erica cinerea and C. vulgaris found in heather-gorse vegetation communities in the end of the grazing season. Diet components were harvested daily from random sites within the experimental field and were offered twice daily in individual mangers a total daily amount of $1.0 \mathrm{~kg} \mathrm{DM} / 100 \mathrm{~kg}$ LW.

Animals were housed in individual pens for 7 day's adaptation to diets, followed by 4 days of collection of representative samples of each plant species and animal faeces. Prior to the trial, animals were grazing on the type of vegetation described for these marginal areas, which was used in the experimental diets. Daily total faecal output was recorded individually. One sample of total faeces was collected from each animal every day for DM determination (i.e., using a forced-air oven at $60{ }^{\circ} \mathrm{C}$ for $72 \mathrm{~h}$ ) and another sample was immediately frozen at $-20^{\circ} \mathrm{C}$ and then freeze-dried and milled through a $1 \mathrm{~mm}$ screen. After alkane analysis (Ferreira et al., 2007a), all samples were vacuumpacked in plastic containers.

\subsection{Long-chain fatty acid analysis}

Long-chain fatty acid concentrations of diet components and faeces were analysed in duplicate according to the methods of Dove and Mayes (2006). The first stage involved treating $0.2 \mathrm{~g}$ of faeces or $0.5 \mathrm{~g}$ of diet components for $16 \mathrm{~h}$ with 3 or $4 \mathrm{~mL}$ ethanolic $\mathrm{KOH}(1 \mathrm{M})$ at $90{ }^{\circ} \mathrm{C}$, respectively, in a dry-block heater (Techne DB-3, Techne Ltd., Duxford, Cambridge, UK). Afterwards, a hot extraction was performed with heptane and water at $60{ }^{\circ} \mathrm{C}$ to remove hydrocarbons (including alkanes) and long-chain fatty alcohols ( $\mathrm{LCOH})$. After the extraction, the aqueous residue from the $\mathrm{LCOH}$ extraction was acidified with $1.5 \mathrm{~mL}$ of $5.8 \mathrm{M} \mathrm{HCl}$ and extracted with heptane/diethyl ether (50:50, v/v). To purify the LCFA extract, $2 \mathrm{~mL}$ of heptane was added and $0.5 \mathrm{~mL}$ of the extract was passed through a silica-gel column (Alltech Associates, Deerfield, IL, USA). The silica-gel column was washed with heptane-ethyl acetate (92:8, v/v) and the elution of LCFA was accomplished with the addition of heptane/ethyl acetate (70:30, v/v). Samples eluted from the columns were evaporated to dryness. To convert the LCFA to their fatty acid methyl esters, $1 \mathrm{~mL}$ toluene and $2 \mathrm{~mL}$ of methanol, previously acidified with sulphuric acid, were added to the dried elute which was kept at $50{ }^{\circ} \mathrm{C}$ overnight. After cooling, $2 \mathrm{~mL}$ of an aqueous solution of $0.5 \mathrm{M} \mathrm{K}_{2} \mathrm{CO}_{3}$ and 
$2 \mathrm{~mL}$ of heptane were added and the top organic layer was removed and evaporated to dryness. Fatty acid methyl ester extracts were redissolved with $0.2 \mathrm{~mL}$ of heptane (kept at room temperature) for chromatographic analysis.

Analysis of the LCFA $\left(\mathrm{C}_{22}-\mathrm{C}_{34}\right)$ was carried out by gas chromatography-mass spectrometry (GC-MS), using an Agilent $6890 \mathrm{~N}$ (Agilent Technologies, Santa Clara, CA, USA) GC equipped with a $5973 \mathrm{~N}$ mass spectrometer and an Agilent 7683 automatic liquid sampler injector. The target analytes were separated using a DB-1 capillary column, $30 \mathrm{~m} \times 0.25 \mathrm{~mm}$ with $0.25 \mu \mathrm{m}$ film thickness (Agilent Technologies, USA). Injection volume was $1 \mu \mathrm{L}$ (splitless, $0.5 \mathrm{~min}$ ) and the injector temperature was $280^{\circ} \mathrm{C}$. The column was maintained at $170{ }^{\circ} \mathrm{C}$ for $4 \mathrm{~min}$ after injection, ramped at $30^{\circ} \mathrm{C} / \mathrm{min}$ up to $215^{\circ} \mathrm{C}$, $1 \mathrm{~min}$ hold, and then ramped at $6{ }^{\circ} \mathrm{C} / \mathrm{min}$ up to $300^{\circ} \mathrm{C}$, where it was held for $20 \mathrm{~min}$. Helium was used as the carrier gas at $34 \mathrm{~cm} / \mathrm{s}$ average linear velocity. Mass spectra were acquired in electron impact mode at $70 \mathrm{eV}$, using full scan with a scan range of 40-800 atomic mass units. All chromatographic analyses were carried out in duplicate for each extract, and a mixed standard was run every 7 sample vials to enable corrections for variation in detector response, as suggested by Dove and Mayes (2006). The mixed standard solution consisted of several fatty acid methyl esters (i.e., methyl behenate, methyl tetracosanoate, methyl hexacosanoate, methyl octacosanoate and methyl triacontanoate) dissolved in heptane. The LCFA concentrations were quantified relative to known amounts of the internal standard hentriacontanoic acid $\left(C_{31}\right)$ dissolved in 50:50 ( v/v) heptane/ethanol $(1.3 \mathrm{mg} / \mathrm{g})$ added at the beginning of the extraction procedure. When not in use both the internal standard and the mixed standard solutions were stored (2$8{ }^{\circ} \mathrm{C}$ ) and kept protected from the light.

\subsection{Calculations}

LCFA and alkane faecal recoveries (FR) were calculated for each animal as the proportion of marker consumed in the diet which was recovered in the faeces.

Diet composition estimates were obtained for each animal using an optimization procedure which minimises the sum of squared discrepancies between the actual (A) LCFA, alkane and LCFA + alkane proportions in faeces (adjusted or not for the incomplete faecal recoveries) and the estimated (E) proportions (different combinations of diet components), according to Salt et al. (1994), based upon the individual marker concentrations expressed as proportions of the total for that marker.

Estimates were based on LCFA alone $\left(\mathrm{C}_{22}-\mathrm{C}_{34}\right)$, alkanes alone $\left(C_{25}-C_{31}\right.$ and $\left.C_{33}\right)$ or a combination of LCFA with alkanes. The $C_{32}$ alkane was not used for diet composition estimation as it was supplied to E3, E4 and C1 groups for feed intake estimation. For diet composition calculations, different LCFA and alkane FR corrections were applied, being: 1) LCFA and alkane faecal concentrations without any correction for incomplete faecal recovery (FC0); 2) LCFA and alkane faecal concentrations corrected using mean recovery rate of the dietary treatment that the animal belonged to (FC1); 3) LCFA and alkane faecal concentrations corrected using mean recovery rate across all experimental diets (FC2).

Apparent in vivo dry matter digestibility $\left(\mathrm{DMD}_{\mathrm{ap}}\right)$ was calculated from total faecal collection using the equation
$\mathrm{DMD}_{\mathrm{ap}}=(I-F) / I$, where $I$ is the total DM intake and $F$ the total DM faecal output.

\subsection{Statistical analysis}

Statistical analyses were performed using GenStat (2008). Differences between plant species in LCFA, alkane and LCFA+ alkane profiles were explored using Principal Components Analysis (PCA). To assess if the discriminatory information provided by the LCFA markers was additional to that provided by the alkane markers, PC scores obtained with the two different classes of marker were compared by Orthogonal Procrustes Rotation (OPR) as suggested by Bugalho et al. (2004) and Dove and Charmley (2008).

Effects of animal species, diet composition and carbonchain length and their interactions on FR of each LCFA and alkane were examined by ANOVA. Orthogonal contrasts were applied to determine linear and quadratic effects of carbonchain length and its interaction with diet composition effect.

Accuracy of diet composition estimates as a whole was assessed by the Kulczynski similarity index (KSI, Krebs, 1989), i.e., overlap in diet composition between known values and those estimated using different sets of FR correction, as:

$K S I=\frac{\sum 2 c_{i}}{\sum\left(a_{i}+b_{i}\right)}$

where $c_{i}$ is the lesser proportion of $i$ component in the 2 diets (known vs. estimated) and $\left(a_{i}+b_{i}\right)$ is the sum of proportions of each plant component in both diets (known and estimated). Effects of animal species (AS), diet composition (D), faecal recovery correction (FC), marker $(M)$ and their interactions on the KSI values were examined by ANOVA. For multiple comparisons among means Tukey's test was used and differences with a $P$-value of less than 0.05 were considered significant.

\section{Results}

\subsection{LCFA profiles of diet components}

The LCFA and alkane content of plant species offered to the animals in the experimental period are presented in Table 1. The concentrations of alkanes $\mathrm{C}_{22}$ and $\mathrm{C}_{34}$ and $\mathrm{C}_{31}$-LCFA are not shown as they were used as internal standards in GC-MS analyses and $\mathrm{C}_{33}$-LCFA was absent in all plant species. For all diet components, total LCFA concentrations were higher than the alkanes, with heather showing the highest total LCFA concentration ( $4455 \mathrm{mg} / \mathrm{kg} \mathrm{DM})$ and $U$. gallii the lowest one ( $2119 \mathrm{mg} / \mathrm{kg} \mathrm{DM})$. It should be noted that, in general, the individual LCFA concentrations exceeded $100 \mathrm{mg} / \mathrm{kg}$ DM, while the alkane ones rarely exceed $50 \mathrm{mg} / \mathrm{kg} \mathrm{DM}$.

Even-chain LCFA predominated over the odd-chain ones in all diet components, accounting for more than 0.80 of total LCFA, ranging between 0.83 (U. gallii) and 0.88 (L. perenne). For L. perenne and $U$. gallii, shorter LCFA $\left(\mathrm{C}_{22}-\mathrm{C}_{27}\right)$ predominated over the longer ones (i.e., 0.65 and 0.55 , respectively), while for the other woody species (i.e., heather) shorter and longer LCFA showed similar proportions.

The PCA results (data not shown) showed that the first two principal components (PC) explained 1.0 of the variance 
Table 1

Mean ( \pm standard deviation) long-chain fatty acid (LCFA) and alkane content $(\mathrm{mg} / \mathrm{kg} \mathrm{DM})$ of the plant species used in the diets of equines and cattle.

\begin{tabular}{|c|c|c|c|c|c|c|c|}
\hline & \multicolumn{3}{|c|}{ LCFA concentrations } & \multicolumn{4}{|c|}{ Alkane concentrations } \\
\hline & L. perenne & U. gallii & Heather & & L. perenne & U. gallii & Heather \\
\hline $\mathrm{C}_{22}$ & $570 \pm 100.8$ & $603 \pm 68.6$ & $801 \pm 142.9$ & $\mathrm{C}_{25}$ & $11 \pm 1.1$ & $3 \pm 0.6$ & $10 \pm 1.4$ \\
\hline $\mathrm{C}_{23}$ & $148 \pm 29.6$ & $141 \pm 20.6$ & $103 \pm 18.0$ & $C_{26}$ & $3 \pm 0.5$ & $2 \pm 0.3$ & $6 \pm 0.7$ \\
\hline $\mathrm{C}_{24}$ & $447 \pm 54.3$ & $217 \pm 25.3$ & $530 \pm 108.4$ & $\mathrm{C}_{27}$ & $19 \pm 1.5$ & $21 \pm 2.5$ & $33 \pm 6.6$ \\
\hline $\mathrm{C}_{25}$ & $143 \pm 32.9$ & $77 \pm 15.4$ & $249 \pm 70.3$ & $\mathrm{C}_{28}$ & $7 \pm 0.8$ & $11 \pm 1.4$ & $17 \pm 6.3$ \\
\hline $\mathrm{C}_{26}$ & $1002 \pm 132.1$ & $92 \pm 6.0$ & $405 \pm 57.7$ & $\mathrm{C}_{29}$ & $78 \pm 6.4$ & $55 \pm 5.5$ & $109 \pm 19.7$ \\
\hline $\mathrm{C}_{27}$ & $115 \pm 37.7$ & $30 \pm 4.0$ & $127 \pm 52.9$ & $C_{30}$ & $10 \pm 1.5$ & $8 \pm 0.8$ & $27 \pm 4.4$ \\
\hline $\mathrm{C}_{28}$ & $479 \pm 68.1$ & $287 \pm 37.0$ & $456 \pm 149.2$ & $C_{31}$ & $161 \pm 10.7$ & $106 \pm 10.3$ & $654 \pm 123.7$ \\
\hline $\mathrm{C}_{29}$ & $40 \pm 7.3$ & $102 \pm 11.6$ & $65 \pm 8.7$ & $C_{32}$ & $8 \pm 1.2$ & $3 \pm 0.3$ & $55 \pm 5.5$ \\
\hline$C_{30}$ & $458 \pm 98$ & $531 \pm 73.4$ & $747 \pm 86.7$ & $\mathrm{C}_{33}$ & $93 \pm 9.7$ & $4 \pm 1.3$ & $519 \pm 84.7$ \\
\hline $\mathrm{C}_{32}$ & $247 \pm 59.8$ & $38 \pm 6.6$ & $718 \pm 147.7$ & Total & $394 \pm 24.1$ & $220 \pm 31.4$ & $1430 \pm 162.5$ \\
\hline $\mathrm{C}_{34}$ & $96 \pm 10.2$ & $1 \pm 0.6$ & $254 \pm 38.4$ & Total odd-chain & $367 \pm 21.8$ & $195 \pm 26.9$ & $1325 \pm 153.2$ \\
\hline Total & $3745 \pm 366.3$ & $2119 \pm 209.1$ & $4455 \pm 456.5$ & & & & \\
\hline Total even-chain & $3299 \pm 269.6$ & $1769 \pm 175.3$ & $3911 \pm 451.3$ & & & & \\
\hline
\end{tabular}

among plant components when using either data on LCFA, alkanes or LCFA combined with alkanes. Plant species were clearly discriminated when using both LCFA and LCFA combined with alkanes, while L. perenne and U. gallii presented some resemblances in the alkane data as they were located close to each other in a biplot of the first two PC. These results suggested that LCFA markers provided additional discriminatory information to that given by the alkane markers. The OPR results confirmed that this was the case, by demonstrating that when PCA scores based on alkanes or on LCFA were compared, 0.68 of the residual variance remained after rotation.

\subsection{LCFA and alkane faecal recoveries}

The FR results of the LCFA and alkane markers are shown in Tables 2 and 3, respectively. In general, FR of these markers was incomplete, although several alkanes and LCFA presented FR above $100 \%$. It should be noted that FR of $C_{34}$-LCFA was unexpectedly low in E1, E2, C1 and C2 groups (i.e., 0.46, 0.52, 0.62 and 0.44 , respectively) when compared with other equine groups and LCFA with similar carbon-chain length. Mean coefficient of variation (CV) of FR was higher $(P=0.0024)$ in the LCFA than in the alkane markers ( 13.3 vs. $6.9 \%$, respectively) both in equines (13.8 vs. $8.2 \%, P=0.0643$ ) and cattle (12.8 vs. $5.6 \%, P=0.0196)$. Similar $(P>0.05) \mathrm{CV}$ was observed for the odd-chain and even-chain LCFA and alkanes, both in equines and cattle.

The comparison of equine and cattle FR data showed that LCFA behaved differently $(P<0.001$, Table 4$)$ in the digestive tract of equines and cattle. Equines had higher mean FR for all LCFA, ranging between $0.68\left(\mathrm{C}_{34}\right)$ and $0.99\left(\mathrm{C}_{24}\right)$. Differences in LCFA faecal recovery between equines and cattle tended to decrease with carbon-chain length from a maximum of 0.52 $\left(\mathrm{C}_{23}\right)$ to a minimum of $0.09\left(\mathrm{C}_{29}\right)$. Although animal species had no effect on alkane FR (Table 5), equines had higher FR for the shorter alkanes (i.e., $C_{25}$ to $C_{29}$ ), while cattle had higher FR for the longer ones (i.e., $C_{30}$ to $C_{33}$ ).

The LCFA and alkane carbon-chain length had an effect $(P<0.001)$ on the FR (Tables 4 and 5 , respectively) although their relationship varied between animal species. In equines, LCFA and alkane FR tended to decrease with carbon-chain length $(\mathrm{C})$ in a curvilinear fashion $\left(P<0.001, \mathrm{FR}=-0.52+0.119 \mathrm{C}-0.0024 \mathrm{C}^{2}\right.$,
$R^{2}$ adjusted $=0.176 ; \quad P<0.001, \quad F R=4.03-0.193 C+0.003 C^{2}$, $R^{2}$ adjusted $=0.219$, respectively; Fig. 1$)$ as the quadratic term was significant $(P<0.01)$ for both markers, except for the evenchain alkanes (Table 5) where a linear association $(P<0.001$, $\mathrm{FR}=2.216-0.042 \mathrm{C}, R^{2}$ adjusted $\left.=0.376\right)$ was observed. It should be emphasized that the curvilinearity observed between the carbon-chain length and LCFA FR (Fig. 1) in equines was a result of the unexpectedly low $F R$ of $C_{34}$-LCFA. In fact, when $\mathrm{C}_{34^{-}}$ LCFA was excluded from the analysis the quadratic term was no longer significant $(P=0.200)$ and the equation slope $(-0.009 \pm$ $0.005)$ did not differ $(P=0.0632)$ from zero. By contrast, in cattle both markers FR tended to increase with carbon-chain length in a curvilinear $\left(P<0.001, \mathrm{FR}=-2.44+0.212 \mathrm{C}-0.0036 \mathrm{C}^{2}, R^{2}\right.$ adjusted $=0.120)$ and linear fashion $(P<0.001, F R=0.112+$ $0.028 \mathrm{C}, R^{2}$ adjusted $=0.550$ ) for LCFA and alkanes, respectively. As a result, the interaction between animal species and carbonchain length was highly significant $(P<0.001)$ for the LCFA and alkane FR (Tables 4 and 5 , respectively).

Results also showed an effect $(P<0.001)$ of diet composition on the LCFA and alkane FR (Tables 4 and 5, respectively). In general, the inclusion of gorse in the equines diets (i.e., E3 and E4) resulted in an increase of the FR of both LCFA and alkanes, whereas the inclusion of the other woody species (i.e., heather) in the cattle diets resulted in an increase of LCFA FR (Table 2) and a decrease of the alkane FR (Table 3). Also, an interaction between diet composition and carbon-chain length of both markers was observed, indicating a different FR pattern between diets in both animal species. For the LCFA, the analysis for each individual marker indicated an effect of diet composition on FR, expect for $C_{23}$ and $C_{29}$ in equines and $C_{26}, C_{27}$ and $\mathrm{C}_{28}$ in cattle. This effect was not so clear in the alkane markers, being significant for $C_{25}$ and $C_{26}$ in cattle, $C_{31}$ in equines, and $C_{27}$ and $\mathrm{C}_{33}$ in both animal species.

\subsection{Diet composition estimates}

Diet composition estimates obtained based on LCFA and alkanes alone, and the combination of both markers for equines and cattle are illustrated in Figs. 2 and 3, respectively. Similar $(P=0.439)$ level of accuracy was observed in equines $(94.8 \%)$ and cattle (95.3\%). The use of different marker data influenced $(P<0.001)$ the accuracy (assessed by the KSI values) of the diet composition estimates in equines $(P=0.0122)$ and cattle 


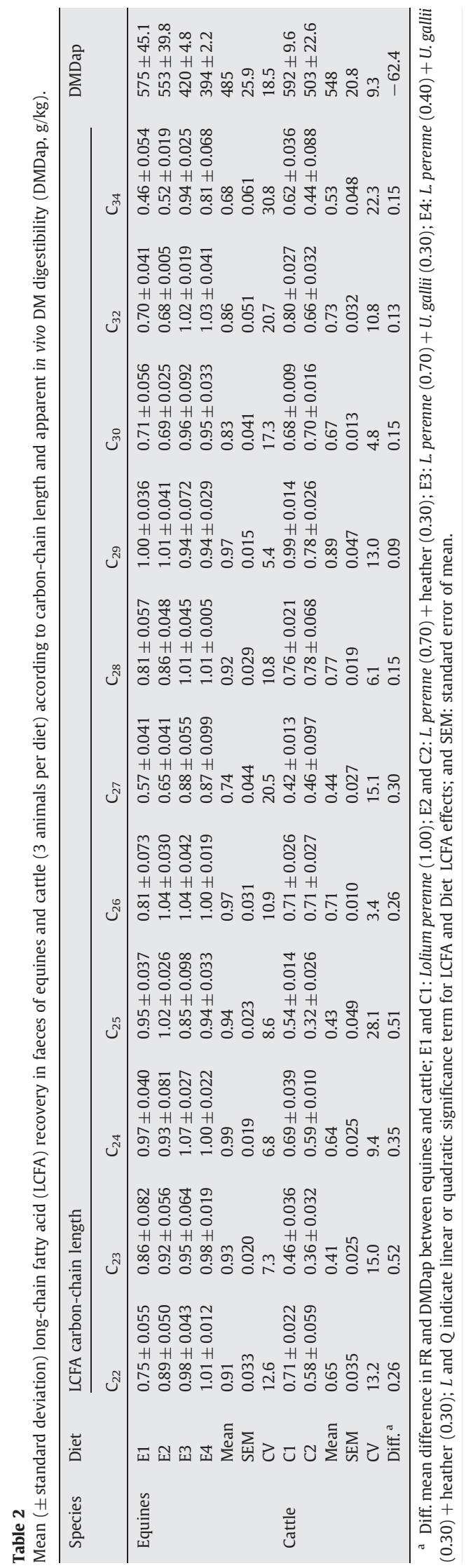

$(P<0.001)$. The combination of LCFA and alkane data resulted in more accurate $(P<0.05)$ diet composition estimates in both animal species (96.2 and $97.7 \%$ for equines and cattle, respectively). In equines, the use of LCFA or alkanes alone resulted in similar estimates of diet composition (mean KSI indexes of 94.3 and 93.9\%, respectively). By contrast, LCFA estimates in cattle $(95.2 \%)$ were more accurate $(P<0.05)$ than those obtained using the alkane data (93.0\%). As a result, an interaction $(P<0.001)$ between marker type and animal species was observed.

The accuracy of diet composition estimates was also affected $(P<0.001)$ by the diet composition. As expected, higher $(P<0.05)$ KSI indexes were observed in the less complex diet, i.e., composed only by $L$. perenne (i.e., E1 and $\mathrm{C} 1$ ) for both equines (96.2\%) and cattle (96.4\%). No interaction $(P=0.287)$ between diet composition and animal species was observed, whereas an interaction $(P<0.001)$ between marker data and diet composition was found.

For both animal species, the utilization of uncorrected marker faecal concentrations (FCO) and those corrected with mean recovery rate across all experimental diets (FC2) resulted in the worst $(P<0.05)$ estimates of diet composition when using LCFA data, alkane data and their combination. By contrast, high levels of accuracy were observed when using more accurate faecal corrections (i.e., FC1) with mean KSI indexes of 96.4 and $98.6 \%$ for equines and cattle, respectively. In general, the application of FCO and FC2 corrections to LCFA, alkanes and LCFA + alkanes faecal concentrations resulted in an underestimation of L. perenne proportions in the diets, although in some occasions accurate estimates of diet composition were observed when applying these faecal corrections. As a result, an interaction between faecal correction and diet composition was found $(P<0.001)$.

\section{Discussion}

\subsection{Marker profiles of the plant species}

Results obtained in this study showed large differences in the LCFA and alkane profiles between plant species used as possible diet components, as previously reported for these epicuticular markers and plant species (Dove and Mayes, 2005; Ferreira et al., 2009a,b, 2010). Although L. perenne and U. gallii had similarities in the alkane profiles, they were clearly discriminated by the LCFA markers. Ali et al. (2005) and Ferreira et al. (2009a, 2010) also indicated that plant species with a similar pattern in one marker may differ in the pattern of a different marker. One important aspect that needs to be considered when combining different types of markers is if they are supplying similar discriminatory information or different and complementary data. In the present study, results suggested that LCFA markers provided additional discriminatory information to that given by the alkane markers, as also observed by Ferreira et al. (2009a).

Alkane and LCFA profiles of the plant species were quite different in terms of total marker concentrations and in the predominance of odd-chain or even-chain markers. In fact, LCFA markers had between 3.4 (heather), 10.2 (L. perenne) and 10.9 ( $U$. gallii) times higher total concentrations than the alkanes. These results are consistent with those found in these plant species in previous reports by Ferreira et al. (2009a, 2010) 
Table 3

Mean ( \pm standard deviation) alkane recovery in faeces of equines and cattle ( 3 animals per diet) according to carbon-chain length and apparent in vivo DM digestibility (DMDap, g/kg).

\begin{tabular}{|c|c|c|c|c|c|c|c|c|c|c|}
\hline \multirow[t]{2}{*}{ Species } & \multirow[t]{2}{*}{ Diet } & \multicolumn{8}{|c|}{ Alkane carbon-chain length } & \multirow[t]{2}{*}{ DMDap } \\
\hline & & $\mathrm{C}_{25}$ & $\mathrm{C}_{26}$ & $\mathrm{C}_{27}$ & $\mathrm{C}_{28}$ & $\mathrm{C}_{29}$ & $C_{30}$ & $\mathrm{C}_{31}$ & $\mathrm{C}_{33}$ & \\
\hline \multirow[t]{7}{*}{ Equines } & E1 & $0.94 \pm 0.058$ & $1.06 \pm 0.176$ & $0.87 \pm 0.035$ & $1.01 \pm 0.073$ & $0.88 \pm 0.025$ & $0.86 \pm 0.158$ & $0.88 \pm 0.038$ & $0.85 \pm 0.023$ & $575 \pm 45.1$ \\
\hline & E2 & $1.03 \pm 0.105$ & $1.19 \pm 0.045$ & $0.95 \pm 0.081$ & $1.09 \pm 0.117$ & $0.95 \pm 0.080$ & $0.92 \pm 0.028$ & $0.95 \pm 0.072$ & $0.92 \pm 0.053$ & $553 \pm 39.8$ \\
\hline & E3 & $1.12 \pm 0.070$ & $1.12 \pm 0.062$ & $0.99 \pm 0.064$ & $1.04 \pm 0.052$ & $0.95 \pm 0.036$ & $0.99 \pm 0.032$ & $0.95 \pm 0.022$ & $0.98 \pm 0.051$ & $420 \pm 4.8$ \\
\hline & E4 & $1.16 \pm 0.018$ & $1.09 \pm 0.040$ & $1.04 \pm 0.038$ & $1.03 \pm 0.054$ & $0.98 \pm 0.017$ & $1.02 \pm 0.031$ & $1.01 \pm 0.025$ & $1.05 \pm 0.044$ & $394 \pm 2.2$ \\
\hline & Mean & 1.06 & 1.12 & 0.96 & 1.04 & 0.94 & 0.95 & 0.95 & 0.95 & 485 \\
\hline & SEM & 0.031 & 0.028 & 0.024 & 0.021 & 0.016 & 0.028 & 0.018 & 0.025 & 25.9 \\
\hline & $\mathrm{CV}$ & 10.2 & 8.6 & 8.7 & 7.0 & 5.8 & 10.1 & 6.5 & 9.0 & 18.5 \\
\hline \multirow[t]{6}{*}{ Cattle } & $\mathrm{C} 1$ & $0.73 \pm 0.028$ & $0.82 \pm 0.025$ & $0.79 \pm 0.020$ & $0.86 \pm 0.010$ & $0.91 \pm 0.015$ & $0.95 \pm 0.013$ & $0.97 \pm 0.012$ & $0.99 \pm 0.016$ & $592 \pm 9.6$ \\
\hline & $\mathrm{C} 2$ & $0.84 \pm 0.019$ & $1.00 \pm 0.045$ & $0.89 \pm 0.014$ & $0.90 \pm 0.060$ & $0.88 \pm 0.024$ & $0.98 \pm 0.031$ & $0.96 \pm 0.029$ & $1.11 \pm 0.032$ & $503 \pm 22.6$ \\
\hline & Mean & 0.78 & 0.91 & 0.84 & 0.88 & 0.89 & 0.96 & 0.96 & 1.05 & 548 \\
\hline & SEM & 0.026 & 0.042 & 0.022 & 0.018 & 0.009 & 0.010 & 0.009 & 0.029 & 20.8 \\
\hline & $\mathrm{CV}$ & 8.2 & 11.2 & 6.5 & 4.9 & 2.5 & 2.6 & 2.2 & 6.8 & 9.3 \\
\hline & Diff. $^{a}$ & 0.28 & 0.21 & 0.12 & 0.16 & 0.05 & -0.01 & -0.01 & -0.10 & -62.4 \\
\hline
\end{tabular}

a Diff. mean difference in FR and DMDap between equines and cattle; E1 and C1: Lolium perenne (1.00); E2 and C2: L. perenne (0.70) + heather (0.30); E3: L. perenne $(0.70)+U$. gallii $(0.30)$; E4: L. perenne $(0.40)+U$. gallii $(0.30)$ t heather $(0.30)$; L and Q indicate linear or quadratic significance term for alkane and Diet alkane effects; SEM: standard error of mean.

and in native Chinese grass species (Leymus chinensis, Leymus dasystachys and Elymus sibiricum) by Lin et al. (2009). Also Ali et al. (2005) observed higher LCFA total concentrations in 25 rangeland species from Sudan, ranging between a minimum of 2.8 (Ocimum basilicum) to a maximum of 38.5 (Balanites aegyptiaca) times higher LCFA total concentrations. Differences between plant species in total marker concentrations were also observed. Heather had the highest total concentrations for both LCFA and alkanes, whereas $U$. gallii was characterized by lower total marker concentrations. It should be noted that, in general, individual LCFA concentrations were higher than $100 \mathrm{mg} / \mathrm{kg}$ of DM, while only the alkane $C_{31}$ exceeded this value in all plant species. Very low concentrations are considered an important limitation for any chemical compound to be used as a diet composition marker as their less accurate analytical measurements could interfere with diet composition estimation. Besides the herbaceous species and $U$. gallii used in this study, Phalaris aquatica (Charmley and Dove, 2007) and the conifers Picea and Pinus (Dove and Mayes, 2006) are plant species known to be characterized by very low alkane concentrations.

Results also showed that the even-chain LCFA prevailed over the odd-chain ones, representing over $83 \%$ of the total
LCFA content. These results contrast with those obtained for the alkane markers, where the odd-chain accounted for more than $89 \%$ of the total alkane concentrations. Although data on odd-chain LCFA are not presented, Dove and Mayes (2006) suggested the dominance of even-chain fraction not only in LCFA but also in LCOH markers.

\subsection{Marker faecal recovery}

Although some LCFA and alkane markers had a faecal recovery of 1.0, in general the results showed an incomplete faecal recovery of both markers in the faeces of equines and cattle. Faecal recovery values above 1.0 are as "biologically" unexplainable since to date there is no evidence of synthesis of alkane and fatty acids within this range of carbon-chain length in the digestive tract of both ruminant and nonruminant species. In the case of alkanes, these results could be due to a higher degree of potential analytical error associated with their very low concentrations in the diet components and faeces (Dove and Mayes, 2005), especially for the evenchain and shorter alkanes, which could have led to more inaccurate estimates of their faecal recovery.

Table 4

Effect of diet composition, animal species, LCFA carbon-chain length and their interaction on LCFA faecal recovery.

\begin{tabular}{|c|c|c|c|c|c|c|c|c|c|c|}
\hline \multirow[t]{2}{*}{ Effects } & \multicolumn{3}{|c|}{ LCFA data } & \multirow[t]{2}{*}{ Effects } & \multicolumn{3}{|l|}{ Equines } & \multicolumn{3}{|l|}{ Cattle } \\
\hline & All & Odd- & Even- & & All & Odd- & Even- & All & Odd- & Even- \\
\hline$D$ & $<0.001$ & $<0.001$ & $<0.001$ & D & $<0.001$ & 0.006 & $<0.001$ & $<0.001$ & $<0.001$ & $<0.001$ \\
\hline AS & $<0.001$ & $<0.001$ & $<0.001$ & & & & & & & \\
\hline $\mathrm{CCL}$ & $<0.001$ & $<0.001$ & $<0.001$ & CCL & $<0.001$ & $<0.001$ & $<0.001$ & $<0.001$ & $<0.001$ & $<0.001$ \\
\hline$L$ & $<0.001$ & $<0.001$ & $<0.001$ & $L$ & $<0.001$ & 0.413 & $<0.001$ & $<0.001$ & $<0.001$ & 0.025 \\
\hline$Q$ & $<0.001$ & $<0.001$ & $<0.001$ & $Q$ & $<0.001$ & $<0.001$ & $<0.001$ & $<0.001$ & $<0.001$ & $<0.001$ \\
\hline$D^{*} \mathrm{AS}$ & $<0.001$ & $<0.001$ & $<0.001$ & & & & & & & \\
\hline$D^{*} C C L$ & $<0.001$ & $<0.001$ & $<0.001$ & $D^{*} C C L$ & $<0.001$ & $<0.001$ & $<0.001$ & $<0.001$ & $<0.001$ & $<0.001$ \\
\hline$L$ & 0.029 & $<0.001$ & $<0.001$ & $L$ & $<0.001$ & 0.739 & $<0.001$ & 0.748 & 0.661 & 0.355 \\
\hline$Q$ & $<0.001$ & $<0.001$ & $<0.001$ & $Q$ & $<0.001$ & 0.078 & $<0.001$ & $<0.001$ & 0.067 & $<0.001$ \\
\hline $\mathrm{AS}^{*} \mathrm{CCL}$ & $<0.001$ & $<0.001$ & $<0.001$ & & & & & & & \\
\hline$L$ & $<0.001$ & $<0.001$ & $<0.001$ & & & & & & & \\
\hline$Q$ & 0.171 & 0.055 & 0.224 & & & & & & & \\
\hline
\end{tabular}

D diet; AS animal species; CCL carbon-chain length; $L$ linear; and $Q$ quadratic. 
Table 5

Effect of diet composition, animal species, alkane chain length and their interaction on alkane faecal recovery.

\begin{tabular}{|c|c|c|c|c|c|c|c|c|c|c|}
\hline \multirow[t]{2}{*}{ Effects } & \multicolumn{3}{|c|}{ Alkane data } & \multirow[t]{2}{*}{ Effects } & \multicolumn{3}{|l|}{ Equines } & \multicolumn{3}{|l|}{ Cattle } \\
\hline & All & Odd- & Even- & & All & Odd- & Even- & All & Odd- & Even- \\
\hline$D$ & $<0.001$ & $<0.001$ & $<0.001$ & $D$ & $<0.001$ & $<0.001$ & 0.189 & $<0.001$ & $<0.001$ & $<0.001$ \\
\hline AS & $<0.001$ & 0.156 & $<0.001$ & & & & & & & \\
\hline $\mathrm{CCL}$ & $<0.001$ & $<0.001$ & 0.001 & $\mathrm{CCL}$ & $<0.001$ & $<0.001$ & $<0.001$ & $<0.001$ & $<0.001$ & 0.005 \\
\hline$L$ & 0.125 & 0.067 & $<0.001$ & $L$ & $<0.001$ & $<0.001$ & $<0.001$ & $<0.001$ & $<0.001$ & 0.025 \\
\hline Q & 0.002 & $<0.001$ & 0.576 & $Q$ & 0.010 & $<0.001$ & 0.726 & 0.057 & 0.024 & 0.007 \\
\hline$D^{*} A S$ & 0.552 & 0.449 & 0.889 & & & & & & & \\
\hline$D^{*} \mathrm{CCL}$ & $<0.001$ & $<0.001$ & 0.601 & $D^{*} \mathrm{CCL}$ & 0.358 & 0.668 & 0.499 & $<0.001$ & $<0.001$ & 0.005 \\
\hline$L$ & $<0.001$ & $<0.001$ & 0.293 & $L$ & 0.605 & 0.683 & 0.253 & 0.003 & 0.164 & 0.003 \\
\hline Q & 0.006 & 0.001 & 0.863 & $Q$ & 0.168 & 0.086 & 0.764 & $<0.001$ & $<0.001$ & 0.088 \\
\hline $\mathrm{AS}^{*} \mathrm{CCL}$ & $<0.001$ & $<0.001$ & $<0.001$ & & & & & & & \\
\hline$L$ & $<0.001$ & $<0.001$ & $<0.001$ & & & & & & & \\
\hline$Q$ & 0.698 & 0.955 & 0.057 & & & & & & & \\
\hline
\end{tabular}

D diet; AS animal species; CCL carbon-chain length; $L$ linear; and $Q$ quadratic.

Our data suggest that LCFA and alkanes behave differently in the digestive tract of equines and cattle. Although to the authors' knowledge there are no published faecal recovery data of LCFA in equines, results obtained for alkanes in nonruminant species (Sehested et al., 1999; Ordakowski et al., 2001; Monks et al., 2005) showed absence of any systematic relationship between chain length and the faecal recovery. By
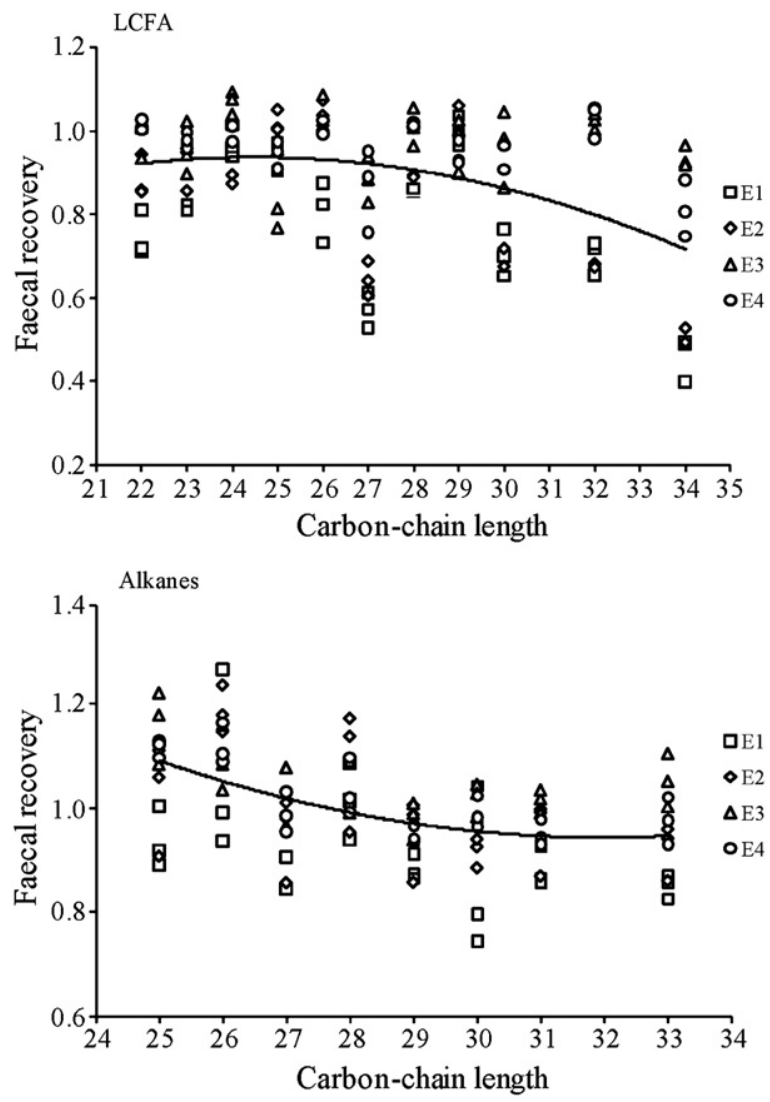

Fig. 1. Relationship between the carbon-chain length of long-chain fatty acids (LCFA) and alkanes with their faecal recovery observed in the equine groups (E1 to E4). contrast, Smith et al. (2007) and Ferreira et al. (2009b) observed an increase of alkane faecal recovery with alkane carbon-chain length in equids.

The comparison of marker faecal recovery between animal species indicated that, in general it was higher in equines, except for the longer alkanes $\left(C_{30}\right.$ to $\left.C_{33}\right)$ as a result of a positive association between carbon-chain length and the faecal recovery of both markers in cattle. A similar trend was observed for other ruminant species in LCFA (Ali et al., 2004; Ferreira et al., 2009a, 2010), alkanes (Ferreira et al., 2005; Charmley and Dove, 2007; Elwert et al., 2008) and LCHO (Dove and Charmley, 2008). Differences between animal species in the faecal recovery pattern of both markers could have an impact on subsequent diet composition estimates based on uncorrected marker faecal concentrations. In fact, it is expected that cattle diet composition estimates can be more prone to bias towards the plant species with predominance of longer markers with higher faecal recoveries.

Results also showed an effect of diet composition on the faecal recovery of both markers in both animal species. Although Ferreira et al. (2007b) referred that this effect will depend on the particular species comprising the diets, these results are similar to those obtained for these markers in goats (Ferreira et al., 2005, 2009a) and sheep (Ferreira et al., 2010) fed on the same vegetation species used in the present trial. Also, Charmley and Dove (2007) observed a diet composition effect on the alkane faecal recovery of sheep fed with diets comprising Trifolium subterraneum, P. aquatica, Lolium rigidum and Triticum aestivum straw. By contrast, a lack of diet composition effect on the alkane faecal recovery was observed in other studies conducted in cattle (Hendricksen et al., 2003; Brosh et al., 2003), goats (Brosh et al., 2003) and sheep (Elwert et al., 2008).

In equines, the FR of both markers was negatively related with diet digestibility as a decrease of the disappearance of markers from the digestive tract with a decrease of diet digestibility was observed (Fig. 4). The lowest diet digestibility values were observed in diets composed by the woody species (i.e., heather and $U$. gallii), characterized by high levels of lignin (mean content of 341 and $217 \mathrm{~g} / \mathrm{kg} \mathrm{DM}$ ). As these phenolic compounds are responsible for the linkages of cuticle and the cell wall components (Himmelsbach, 1993), it is expectable that cuticular waxes will be less accessible to the degradation in vegetation species with higher lignin content. These findings are in 


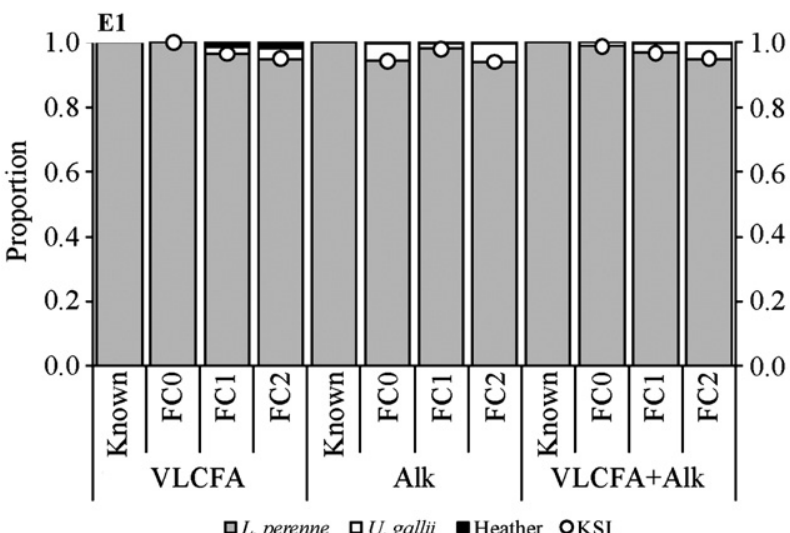

E2

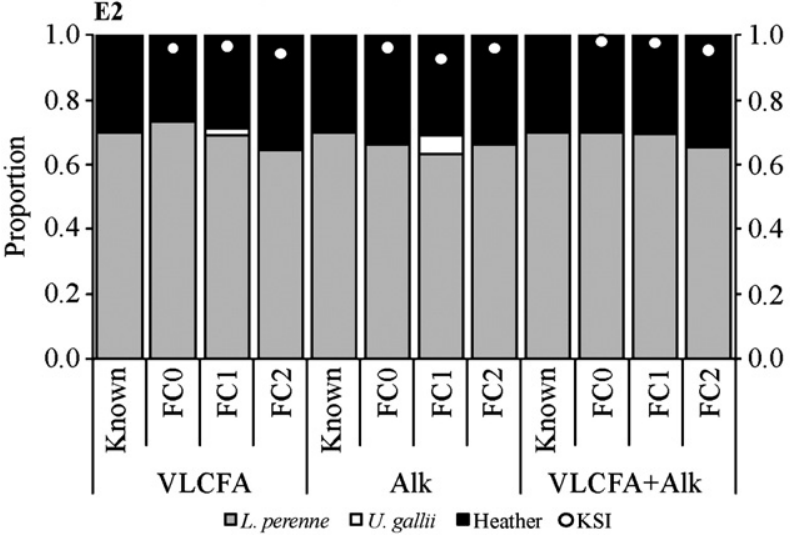

E3

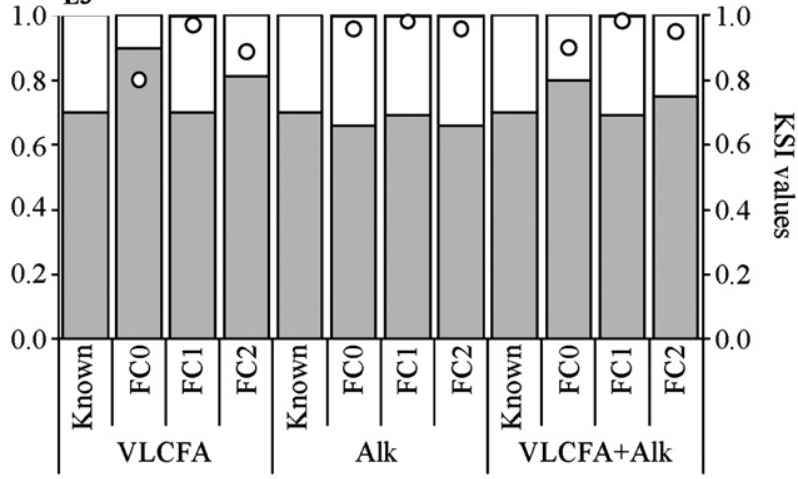

口L. perenne $\mathbf{\square} U$.gallii $\mathbf{m e a t h e r}$ OKSI

$\mathbf{E 4}$

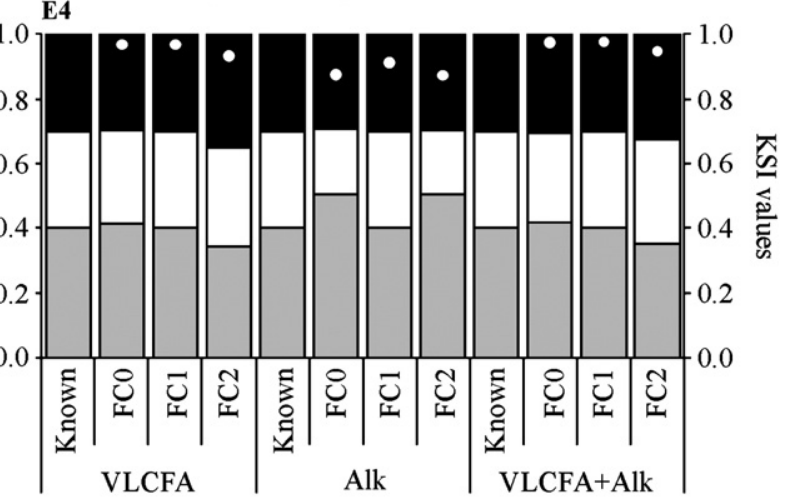

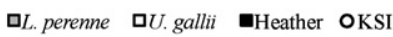

Fig. 2. Comparisons of known and estimated proportions of dietary components obtained using different marker data (LCFA, alkanes or LCFA + alkanes) and faecal recovery corrections (FC0, FC1 and FC2) for the equine groups (E1 to E4).

agreement with those obtained elsewhere for the alkane markers (Ferreira et al., 2005; Charmley and Dove, 2007; Elwert et al., 2008). In opposition, results in cattle were rather contradictory. Although a higher but not significant alkane faecal recovery was observed in the diet with lower digestibility (i.e., L. perenne and heather), in the LCFA a positive association between diet digestibility and LCFA faecal recovery was detected. It should be noted that the range of diet digestibility in cattle was low (503 to
$592 \mathrm{~g} / \mathrm{kg}$ DM) and, for that reason, a consistent conclusion cannot be drawn.

\subsection{Diet composition estimates}

Results obtained in this study for both animal species showed higher levels of accuracy of diet composition estimates when LCFA and alkanes were combined, suggesting
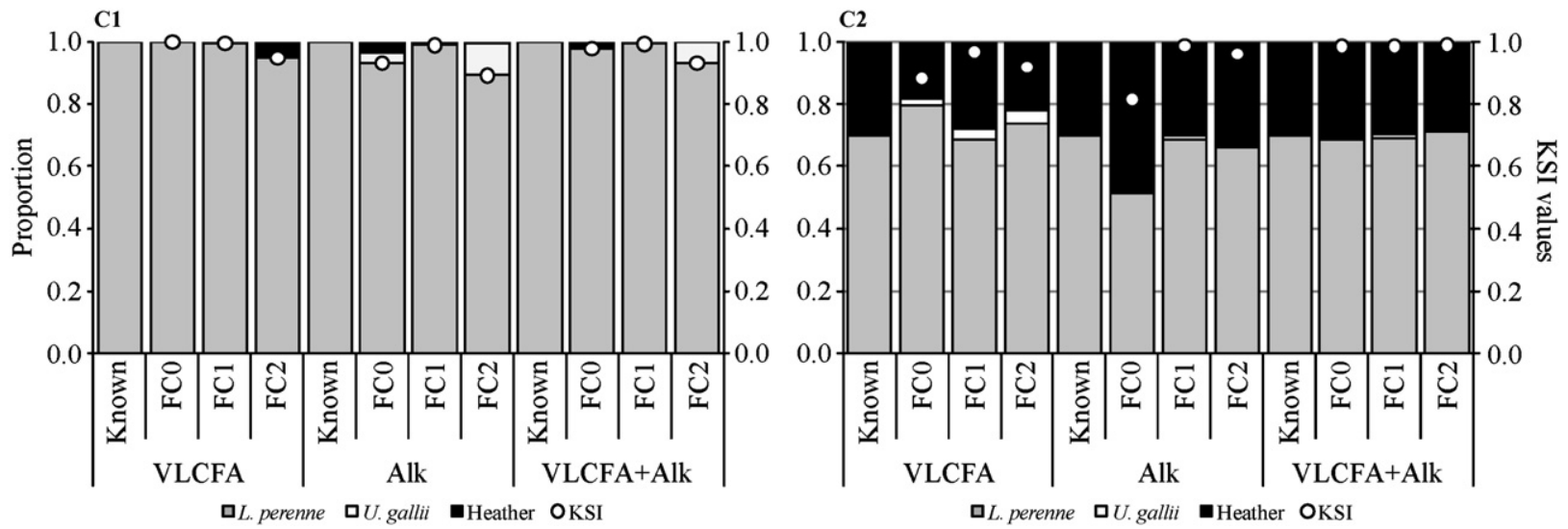

Fig. 3. Comparisons of known and estimated proportions of dietary components obtained using different marker data (LCFA, alkanes or LCFA + alkanes) and faecal recovery corrections ( $\mathrm{FC} 0, \mathrm{FC} 1$ and $\mathrm{FC} 2$ ) for the cattle groups ( $\mathrm{C} 1$ to $\mathrm{C} 2$ ). 

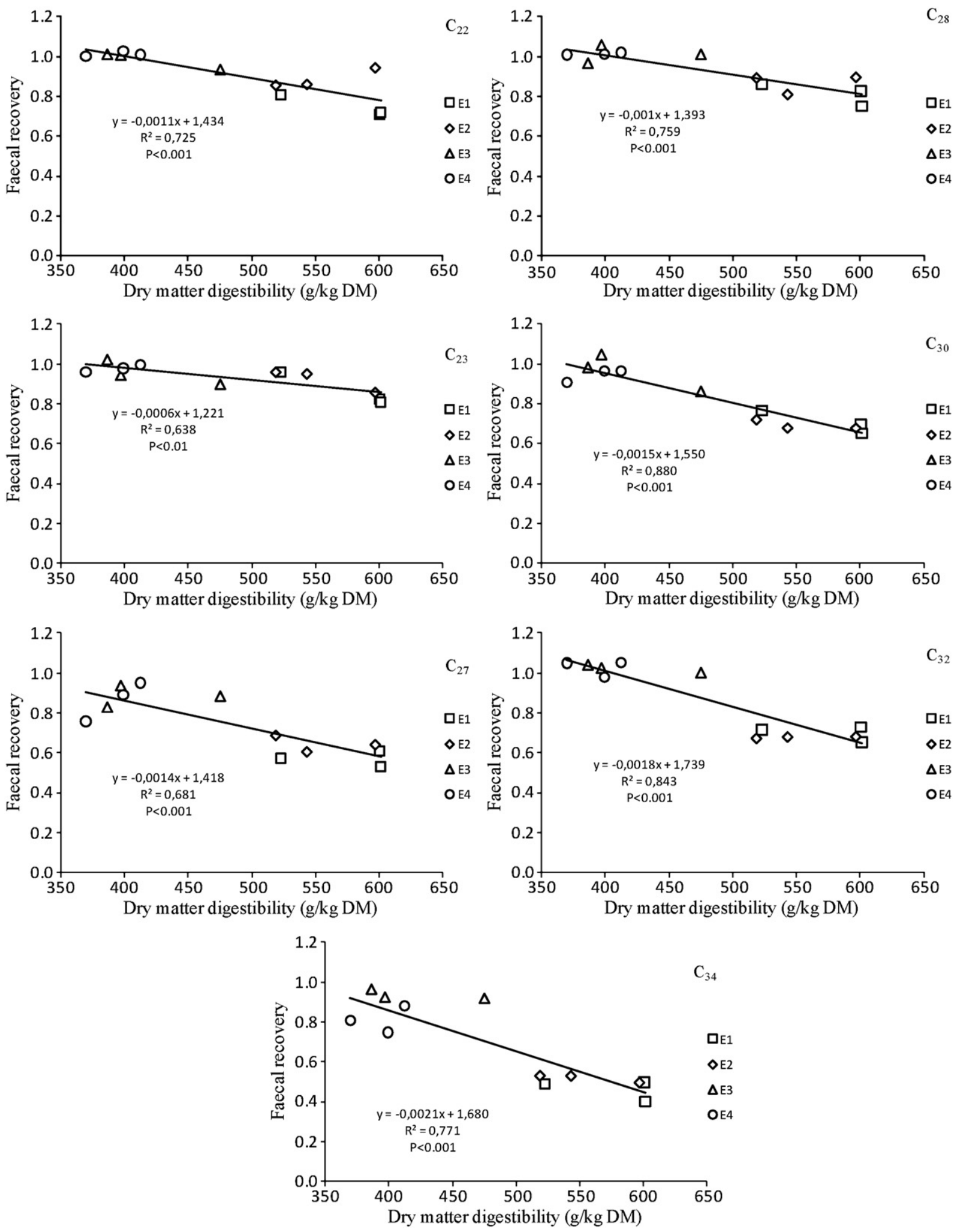

Fig. 4. Relationship between diet digestibility and faecal recovery of the LCFA $C_{22}, C_{23}, C_{27}, C_{28}, C_{30}$, $C_{32}$ and $C_{34}$ observed in the equine diets.

that an increase in the discriminatory power between plant species was achieved with this combination. These results are consistent with those obtained by Kelman et al. (2003) and
Dove and Charmley (2008) when combining alkanes with LCOH, and Ferreira et al. (2009a, 2010) when alkane and LCFA data were used together to estimate diet composition of goats 
and sheep, respectively, fed on the same vegetation components used in the present trial.

The combination of markers is usually suggested in situations where the number of plant species available for animal consumption exceeds the number of alkanes or LCFA available for the calculations (Ferreira et al., 2009b) or when difficulties in distinguishing plant species occur due to a similar maker profiles. For example, Ferreira et al. (2009b) observed similarities in the alkane pattern of Agrostis-Poa leaf fraction, L. perenne, T. repens and "other species" that made their discrimination difficult. Also Oliván et al. (2007) found difficulties in differentiating herbaceous species (L. perenne, $P$. longifolium and A. capillaris) and gorse when alkane markers were used. In these situations, Ferreira et al. (2009a) suggested that the combination of several faecal markers (alkanes, LCFA, LCOH or alkenes) can provide a more specific fingerprint to each plant species, increasing the discriminatory power between them. However, Dove and Charmley (2008) indicated that the combination of markers does not always result in more accurate estimates of diet composition. In the present study, the combination of markers resulted in the most accurate estimates of diet composition for diets E2 (KSI of 97.1\%), E4 (KSI of 96.6\%) and C2 (98.7\%), while LCFA estimates of diet composition were more precise for the animal groups fed only with L. perenne (i.e., E1 and C1 with mean KSI values of 97.1 and $98.1 \%$, respectively). By contrast, although PCA results showed resemblances in the alkane profiles of $L$. perenne and $U$. gallii, and their clear discrimination when using LCFA markers, alkane diet composition estimates for E3 group (mean KSI value of 96.6\%) were more accurate than those obtained by the LCFA $(88.6 \%)$ or LCFA+ alkanes (94.4\%). Further investigation showed a lower correlation between the LCFA profiles of $L$. perenne and $U$. gallii $(0.414)$ than that obtained between their alkane profiles (0.837). These results suggest that PCA analysis on markers profiles should be analysed with caution as a clear discrimination between plant species with this statistical procedure does not mean that accurate estimates of diet composition will be obtained.

The present study can illustrate a practical situation where LCFA or alkanes are selected for a diet composition estimation, and not their combination, as a very low number of possible diet components was used. Results showed that the use of both markers in separate resulted in accurate estimates of diet composition, although higher KSI values were observed with LCFA. These results are in opposition with the higher ability of alkanes than LCFA to estimate diet composition in sheep (Ali et al., 2005; Ferreira et al., 2010) and goats (Ferreira et al., 2009a). In our opinion, the very low alkane concentrations presented in all vegetation components could explain these results as they are more prone to measurement errors (Brosh et al., 2003; Dove and Mayes, 2006), making the discrimination between plant species more difficult (Charmley and Dove, 2007). As L. perenne and $U$. gallii used in this study, other plant species possess very low alkane concentrations (Charmley and Dove, 2007; Ferreira et al., 2009b), especially as the grazing season progressed due to a maturity stage effect on alkane concentrations (Dove et al., 1996), possibly related to a decrease of the leaf fraction in the whole plant, characterized by higher alkane concentrations than the stem fraction (Smith et al., 2001). According to Ferreira et al. (2010) a different ability of markers to distinguish plant species of different diets could explain the lack of superiority of one type of marker to another across the diets used in the present trial.
As expected, for all markers (i.e., LCFA, alkanes and LCFA + alkanes) the most accurate estimates of diet composition were obtained when using treatment mean recovery corrections (i.e., FC1), with mean KSI indexes above $96 \%$ for both animal species, indicating that a suitable correction for incomplete faecal recovery should be used before the application of these markers for diet composition estimation. Higher accuracy can be obtained if individual recovery data are used as they only reflect differences between marker profiles of the diet offered and the diet actually consumed by each animal, and a possible analytical error (Dove and Charmley, 2008). Similar levels of accuracy were observed in studies performed with alkanes (Charmley and Dove, 2007, Ferreira et al., 2005) and LCFA (Ali et al., 2005; Ferreira et al., 2009a, 2010) when this type of faecal correction was used.

Results obtained in this study showed similar accuracy of diet composition estimates obtained using uncorrected marker concentrations (FCO) or those corrected with mean recovery rate across all experimental diets (FC2), differing from those obtained with FC1. Discrepancies between known diet composition proportions and those estimated using FC2 were the result of a high and significant between diet variation (Ferreira et al., 2009a). In a practical perspective, FC2 is generally used to correct marker faecal concentrations as more accurate estimates of faecal recovery (i.e., individual data and FC1) are difficult to obtain in grazing studies. Data showed that if overall recovery data is used in field studies there will be a loss of accuracy in diet composition estimates. In our opinion, the high dependence of these markers on the use of suitable estimates of faecal recovery can be overcome by an increase of the number of markers (Ferreira et al., 2009a), providing a more specific fingerprint for each diet component, as also indicated by Ali et al. (2005) and Lin et al. (2009). To illustrate our suggestion, in this study the accuracy of diet composition estimates obtained with the less suitable faecal corrections (i.e., FC0 and FC2) was higher when LCFA and alkanes were combined than when markers were considered alone, for both animal species. Moreover, the proportion of heather in the diets (E2, E4 and C2) was, in general, estimated with accuracy as a result of a very distinct LCFA and alkane profiles.

Surprisingly, although the association between LCFA and alkane faecal recoveries and carbon-chain length differed between equines (negative) and cattle (positive), diet composition estimates obtained when applying FCO showed similar trends for both animal species. In general, the proportion of $L$. perenne in the diets was overestimated by the LCFA both in equines and cattle, when using uncorrected faecal concentrations. By contrast, the use of FCO in alkanes led to an underestimation of $L$. perenne in both animal species. Although the impact of faecal correction will be a balance between the effect of concentration and the bias toward the markers with higher concentrations, LCFA estimates can be explained by specific features that $L$. perenne had: 1 ) highest concentration on shorter LCFA $\left(\mathrm{C}_{22}-\mathrm{C}_{27}, 0.648\right)$ that had higher faecal recoveries in equines, and 2) highest concentration on even-chain LCFA (0.881) that had higher faecal recoveries in cattle. Thus, it seemed that LCFA estimates tended for the plant species with predominance on the LCFA that had higher faecal recovery, as previously observed by Ferreira et al. (2009a, 2010). Similarly, FC0 alkane estimates in equines tended for the plant species with higher concentration on shorter alkanes (U. gallii, 0.177), 
whereas in cattle they tended for the plant species with higher concentration on the longer ones (heather, 0.952).

Ferreira et al. (2009a) and Dove and Mayes (2005) indicated that faecal recovery correction would have little impact on the accuracy of diet composition estimates when marker recoveries are unaffected by the carbon-chain length, usually observed in non-ruminant herbivores. Results obtained in E4 group when using LCFA markers illustrate this feature, as recovery was not affected by LCFA chain length and accurate estimates of diet composition were obtained.

\section{Conclusions}

Results obtained in this study show a different behaviour of markers in the digestive tract of both animal species. The faecal recovery of both markers was negatively and positively associated with carbon-chain length in equines and cattle, respectively. Results also show that long LCFA can be used as faecal markers to estimate diet composition of equines and cattle fed with herbaceous and woody species if a previous and suitable correction of marker faecal concentrations to incomplete faecal recovery is applied. In our opinion LCFA can be particularly useful in situations where alkane concentrations are low, in particular for much of the plant species found in heathland vegetation communities. Moreover, the use of a more specific fingerprint, provided by marker combination, can result in an improvement of the accuracy of diet composition estimates.

\section{Acknowledgments}

The authors would like to thank to the Carbayal Research Station staff for their help in the field work and to M.J. Martínez and C. Moura for collaboration in the analytical procedures.

\section{References}

Aldezabal, A., 2001. El sistema de pastoreo del Parque Nacional de Ordesa y Monte Perdido (Pirineo Central, Aragón). : Interacción entre la vegetación supraforestal y los grandes herbívoros, vol. 28. Publicaciones del Consejo de Protección de la Naturaleza de Aragón, Zaragoza.

Ali, H.A.M., Mayes, R.W., Hector, B.L., Ørskov, E.R., 2005. Assessment of nalkanes, long-chain fatty alcohols and long-chain fatty acids as diet composition markers: the concentrations of these compounds in rangeland species from Sudan. Anim. Feed Sci. Tech. 121, 257-271.

Ali, H.A.M., Mayes, R.W., Lamb, C.S., Hector, B.L., Verma, A.K., Ørskov, E.R. 2004. The potential of long-chain fatty alcohols and long-chain fatty acids as diet composition markers: development of methods for quantitative analysis and faecal recoveries of these compounds in sheep fed mixed diets. J. Agric. Sci. 142, 71-78.

Brosh, A., Henkin, Z., Rothman, S.J., Aharoni, Y., Orlov, A., Arieli, A., 2003. Effects of faecal $n$-alkane recovery in estimates of diet composition. J. Agric. Sci. 140, 93-100.

Bugalho, M.N., Dove, H., Kelman, W., Wood, J.T., Mayes, R.W., 2004. Plantwax alkanes and alcohols as herbivore diet compositionmarkers. J. RangeManage. 57, 259-268.

Celaya, R., Oliván, M., Ferreira, L.M.M., Martínez, A., García, U., Osoro, K., 2007. Comparison of grazing behaviour, dietary overlap and performance in non-lactating domestic ruminants grazing on marginal heathland areas. Livest. Sci. 106, 271-281.

Charmley, E., Dove, H., 2007. Using plant wax markers to estimate diet composition and intakes of mixed forages in sheep by feeding a known amount of alkane-labelled supplement. Aust. J. Agric. Res. 58, 1215-1225.

Dove, H., Charmley, E., 2008. Using the alkanes and long-chain alcohols of plant cuticularwax to estimate diet composition and the intakes ofmixed forages in sheep consuming a known amount of alkane-labelled supplement. Animal 2, 1474-1485.
Dove, H., Mayes, R.W., 2005. Using n-alkanes and other plant wax components to estimate intake, digestibility and diet composition of grazing/browsing sheep and goats. Small Rum. Res. 59, 123-139.

Dove, H., Mayes, R.W., 2006. Protocol for the analysis of $n$-alkanes and other plantwax compounds and for their use as markers for quantifying the nutrient supply of large mammalian herbivores. Nature Protoc. 4, 1680-1697.

Dove, H., Mayes, R.W., Freer, M., 1996. Effects of species, plant part, and plant age on the $n$-alkane concentrations in the cuticular wax of pasture plants. Aust. J. Agric. Res. 47, 1333-1347.

Duncan, P., Foose, T.J., Gordon, I.J., Gakahu, C.G., Lloyd, M., 1990. Comparative nutrient extraction from forages by grazing bovids and equids: a test of the nutritional model of equid/bovid competition and coexistence. Oecologia 84, 411-418.

Elwert, C., Dove, H., Rodehutscord, M., 2008. Faecal alkane recoveries from multi-component diets and effects on estimates of diet composition in sheep. Animal 2, 125-134.

Ferreira, L.M.M., Carvalho, S., Falco, V., Celaya, R., García, U., Santos, A.S., Rodrigues, M.A.M., Osoro, K., 2009a. Assessment of very long-chain fatty acids as complementary or alternative natural fecal markers to $n$-alkanes for estimating diet composition of goats feeding on mixed diets. J. Anim. Sci. 87, 2732-2745.

Ferreira, L.M.M., Celaya, R., Falco, V., Oliván, M., Santos, A.S., Guedes, C., Rodrigues, M.A.M., Osoro, K., 2010. Evaluation of very long-chain fatty acids and $n$-alkane epicuticular compounds as markers for estimating diet composition of sheep fed heathland vegetation species. Anim. Feed Sci. Technol. 156, 75-88.

Ferreira, L.M.M., García, U., Celaya, R., Rodrigues, M.A.M., Osoro, K., 2009b. Differences between domestic herbivores species in alkane faecal recoveries and the accuracy of subsequent estimates of diet composition. Anim. Feed Sci. Technol. 151, 128-142.

Ferreira, L.M.M., Garcia, U., Rodrigues, M.A.M., Celaya, R., Dias-da-SIlva, A., Osoro, K., 2007a. The application of the $n$-alkane technique for estimating the composition of diets consumed by equines and cattle feeding on upland vegetation communities. Anim. Feed Sci. Technol. 138, 47-60.

Ferreira, L.M.M., Oliván, M., Celaya, R., Garcia, U., Rodrigues, M.A.M., Osoro, K., $2007 \mathrm{~b}$. The use of the alkane technique to estimate diet selection of sheep grazing grass-clover/heather-gorse vegetation communities. J. Sci. Food Agric. 87, 274-285.

Ferreira, L.M.M., Oliván, M., Garcia, U., Rodrigues, M.A.M., Osoro, K., 2005. Validation of the alkane technique to estimate diet selection of goats grazing heather-gorse vegetation communities. J. Sci. Food Agric. 85, 1636-1646.

GenStat, 2008. GenStat, Lawes Agricultural Trust, Rothamsted Experimental Station, 11th ed. VSN International, Oxford, UK.

Hendricksen, R.E., Gazzola, C., Reich, M.M., Roberton, R.F., Reid, D.J., Hill, R.A., 2003. Using molasses as an alternative to controlled release devices for administering $n$-alkane markers to cattle. Anim. Sci. 76, 471-480.

Himmelsbach, D.S., 1993. Structure of forage cell walls-session synopsis. In: Jung, H.G., Buxton, D.R. (Eds.), Forage Cell Wall Structure and Digestibility. Hatfield RD and Ralph J. SSSA Publishing, Madison, pp. 271-283.

Illius, A.W., Gordon, I.J., 1993. Diet selection in mammalian herbivores constraints and tactics. In: Hughes, R.N. (Ed.), Diet selection. : An Interdisciplinary Approach to Foraging Behaviour. Blackwells Scientific Publications, Oxford, pp. 157-181.

Kelman, W., Bugalho, M., Dove, H., 2003. Cuticular wax alkanes and alcohols used as markers to estimate diet composition of sheep (Ovis aries). Biochem. Syst. Ecol. 31, 919-927.

Krebs, C.J., 1989. Ecological Methodology. Harper Collins, New York.

Krysl, L.J., Hubbert, M.E., Sowell, B.F., Plumb, G.E., Jewett, T.K., Smith, M.A., Waggoner, J.W., 1984. Horses and cattle grazing in the Wyoming Red Desert I. Food habits and dietary overlap. J. Range Manag. 37, 72-76.

Lechner-Doll, M., Hume, I.D., Hofmann, R.R., 1995. Comparison of herbivore forage selection and digestion. In: Journet, M., Grenet, E., Farce, M.-H., Theriez, M., Demarquilly, C. (Eds.), Recent Developments in the Nutrition of Herbivores. Proc. of the IVth International Symposium on the Nutrition of Herbivores. INRA Editions, Paris, pp. 231-248.

Lin, L.J., Luo, H.L., Zhang, Y.J., Wang, H., Shu, B., Hong, F.Z., 2009. The potential use of long-chain alcohols 1 and fatty acids as diet composition markers: factors influencing faecal recovery rates and diet composition estimates in sheep. Animal 3, 1605-1612.

Loucougaray, G., Bonis, A., Bouzilé, J.-B., 2004. Effects of grazing by horses and/or cattle on the diversity of coastal grasslands in western France. Biol. Conserv. 116, 59-71.

Menard, C., Duncan, P., Fleurance, G., Georges, J.-Y., Lila, M., 2002. Comparative foraging and nutrition of horses and cattle in European wetlands. J. Appl. Ecol. 39, 120-133.

Monks, A., Payton, I., Efford, M., 2005. Validation of the $n$-alkane technique for estimating diet composition, digestibility and dry matter intake in the brushtail possum (Trichosurus vulpecula). Wildlife Res. 32, 321-331. 
Oliván, M., Ferreira, L.M.M., García, U., Celaya, R., Osoro, K., 2007. Application of $n$-alkanes as diet composition markers in grazing/browsing goats and sheep: effect of using different faecal recovery corrections and plant species grouping approaches. Aust. J. Agric. Res. 58, 1013-1022.

Ordakowski, A.L., Kronfeld, D.S., Holland, J.L., Hargreaves, B.J., Gay, L.S., Harris, P.A., Dove, H., Sklan, D., 2001. Alkanes as internal markers to estimate digestibility of hay or hay plus concentrate diets in horses. J. Anim. Sci. 79, 1516-1522.

Osoro, K., Ferreira, L.M.M., Gracia, U., Celaya, R., 2008. Differences in diet selection and grazing behaviour between equines and cattle grazing on upland vegetation communities. Book of Abstracts of the 59th Annual Meeting of the European Association for Animal Production. Vilnius, Lithuania, p. 140.

Osoro, K., Garcia, U., Jáuregui, B.M., Ferreira, L.M.M., Oliván, M., Celaya, R., 2005. Conducta de pastoreo y variaciones de peso de los herbívoros domésticos en un brezal-tojal parcialmente mejorado. In: Osoro, K., Argamendia, A., Larraceleta, A. (Eds.), Producciones agroganaderas: gestión eficiente y conservación del médio natural (Volumen 1). XLV Reunión Científica de la Sociedad Española para el Estudio de los Pastos, Gijón, pp. 252-258
Osoro, K., García, U., Jáuregui, B.M., Ferreira, L.M.M., Rook, A.J., Celaya, R. 2007. Diet selection and live-weight changes of two breeds of goats grazing on heathlands. Animal 1, 449-457.

Salt, C.A., Mayes, R.W., Colgrove, P.M., Lamb, C.S., 1994. The effects of season and diet composition on the radiocaesium intake by sheep grazing on heather moorland. J. Appl. Ecol. 31, 125-136.

Sehested, J., Breinhild, K.K., Søegaard, K., Vognsen, L., Hansen, H.H., Fernández, J. A., Danielsen, V., Kristensen, V.F., 1999. Use of $n$-alkanes to estimate grass intake and digestibility in sows. In H. Dove and S.W. Coleman (Eds.), Nutritional Ecology of Herbivores. Satellite symposium: emerging techniques for studying the nutrition of free ranging herbivores. San Antonio, Texas, USA (CD-ROM).

Smith, D.G., Mayes, R.W., Hollands, T., Cuddeford, D., Yule, H.H., Malo Ladrero, C.M., Gillen, E., 2007. Validating the alkane pair technique to estimate dry matter intake in equids. J. Agric. Sci. 145, 273-281.

Smith, D.G., Mayes, R.W., Raats, J.G., 2001. Effects of species, plant part, and season of harvest on $n$-alkane concentrations in the cuticular wax of common rangeland grasses from southern Africa. Aust. J. Agric. Res. 52, 875-882. 